\title{
REVIEW
}

\section{Incorporating Incretin-Based Therapies into Clinical Practice for Patients with Type 2 Diabetes}

Joseph M. Tibaldi

To view enhanced content go to www.advancesintherapy.com Received: October 30, 2013 / Published online: February 15, 2014

(c) The Author(s) 2014. This article is published with open access at Springerlink.com

\section{ABSTRACT}

Background: Effective, evidence-based management of type 2 diabetes (T2D) requires the integration of the best available evidence with clinical experience and patient preferences.

Methods: Studies published from 2000 to 2012 evaluating glucagon-like peptide-1 receptor agonists (GLP-1RAs) or dipeptidyl peptidase-4 inhibitors (DPP-4 inhibitors) were identified using PubMed. The author contextualized the study findings with his clinical experience.

Results: Incretin-based therapy targets multiple dysfunctional organs in T2D. Injectable GLP1RAs provide substantial glycemic control and weight reduction; while oral DPP-4 inhibitors provide moderate glycemic control and weight neutrality. Both classes are effective, well tolerated, and associated with a low incidence

Electronic supplementary material The online version of this article (doi:10.1007/s12325-014-0100-5) contains supplementary material, which is available to authorized users.

J. M. Tibaldi ( $\square)$

Diabetes and Endocrine Associates, 59-45 161st

Street Flushing, New York 11365, USA

e-mail: jtibaldi@aol.com of hypoglycemia when used alone or in combination with other antidiabetes agents. GLP-1RAs are associated with transient nausea and, like DPP-4 inhibitors, rare pancreatitis.

Conclusion: Data indicate and clinical experience confirms that incretins are well tolerated in appropriate patients and provide sustained glycemic control and weight loss or weight neutrality throughout T2D progression.

Keywords: Dipeptidyl peptidase-4 inhibitors; Endocrinology; Glucagon-like peptide-1 receptor agonists; Glycemic control; Incretin; Type 2 diabetes; Weight loss

\section{INTRODUCTION}

Incretins [glucagon-like peptide 1 (GLP-1) and glucose-dependent insulinotropic polypeptide (GIP)] are hormones that stimulate insulin secretion, inhibit glucagon secretion, delay gastric emptying, and decrease appetite [1]. They also play an important physiological role in regulating both first- and second-phase insulin responses, which are impaired in patients with type 2 diabetes (T2D) [2]. Recent evidence suggests an approximate $60 \%$ 
reduction in the magnitude of incretin effects in individuals with T2D [2].

Two classes of incretin-based therapies are currently available: injectable GLP-1 receptor agonists (GLP-1RAs) and oral dipeptidyl peptidase-4 inhibitors (DPP-4 inhibitors) [3-11]. The efficacy, tolerability, and clinical use of these agents are described in Tables 1, 2, $3,4,5,6,7,8,9$ [5-33]. Currently available GLP1RAs include liraglutide, exenatide twice daily (exenatide BID), and exenatide once weekly [exenatide extended release (EQW)]. Liraglutide and exenatide BID are administered by pen devices; EQW is administered as a suspension with a 23-gage needle and syringe and requires reconstitution. GLP-1RAs enhance glucosedependent insulin secretion by mimicking the glucoregulatory effects of endogenous GLP-1 and by providing pharmacological (high) levels of GLP-1 activity, and also suppress glucagon release (Fig. 1) [1, 34, 35]. In contrast, DPP-4 inhibitors prevent enzymatic inactivation of endogenous GLP-1, resulting in prolonged availability of physiological levels of native GLP-1 and GIP and modest receptor activation [1]. Sitagliptin, saxagliptin, and linagliptin are the DPP-4 inhibitors currently available in the United States. A fourth DPP-4 inhibitor, alogliptin, has recently been approved. All are administered orally once daily, with or without food.

Incretin-based therapies target most of the dysfunctional organ systems in T2D, potentially improve $\beta$-cell function $[18,22,36]$, have minimal hypoglycemia risk, and are either weight neutral [31] or induce weight loss [15, 29, 37-43]. However, differences in the mechanisms of action and pharmacodynamics/ pharmacokinetics, between and within these classes, can result in important differences in fasting plasma glucose (FPG), postprandial glucose (PPG), body weight, $\beta$-cell function, blood pressure (BP), and safety and tolerability [44], as found in randomized head-to-head clinical trials (Tables 2, 3, 4, 5, 6, 7, 8, 9 [1233]). Numerous reviews have examined the efficacy and tolerability of GLP-1RAs and DPP4 inhibitors based on the results from randomized controlled trials (RCTs) [34, 45-47], but few have focused on comparisons among incretin agents. Moreover, in clinical practice, the appropriate choice of incretin therapy for a given patient is not always clear.

Effective evidence-based decision making requires the integration of clinical experience with the best available clinical evidence, provided by data from either RCTs or systematic research and patient preference [48, 49]. While clinical trials are conducted in highly selective patient populations with limited strategies, treatment of T2D in clinical practice should reflect an individualized, patientcentered approach that considers the preferences, needs, and values of individual patients [3], as indicated by recent treatment guidelines [3, 4]. This review examines the clinical evidence surrounding the use of GLP1RAs and DPP-4 inhibitors in the context of more than 25 years in a general endocrinology practice. Approximately $50-60 \%$ of patients treated in this setting have T2D. It is the objective of this analysis to help clinicians both individualize and optimize incretin therapy in appropriate candidates throughout the progression of T2D.

\section{METHODS}

A PubMed literature search was conducted for randomized, head-to-head, comparative studies published between 2000 and 2012 including GLP-1RAs and DPP-4 inhibitors. In addition, randomized, controlled studies for monotherapy and combination therapy 


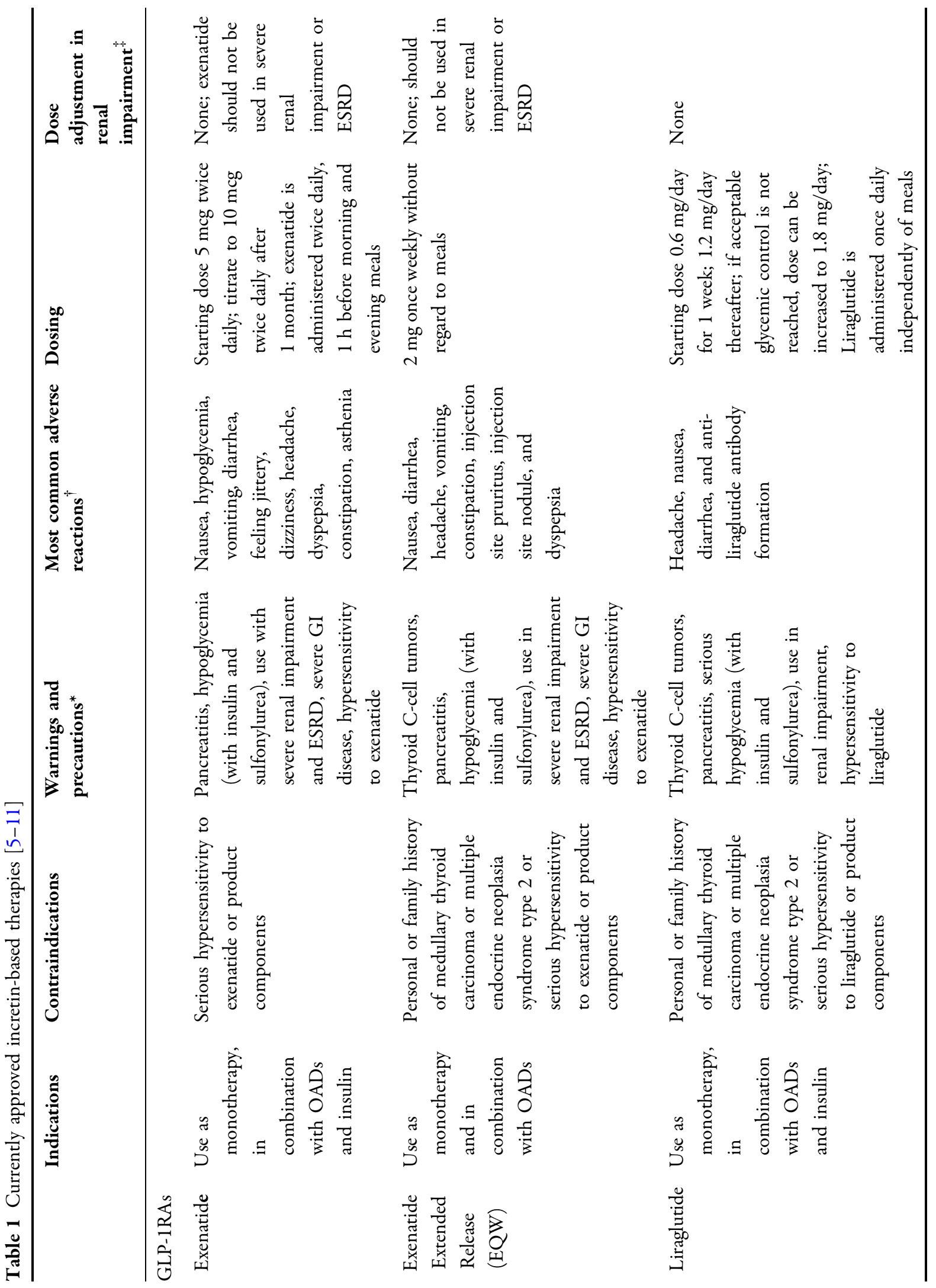




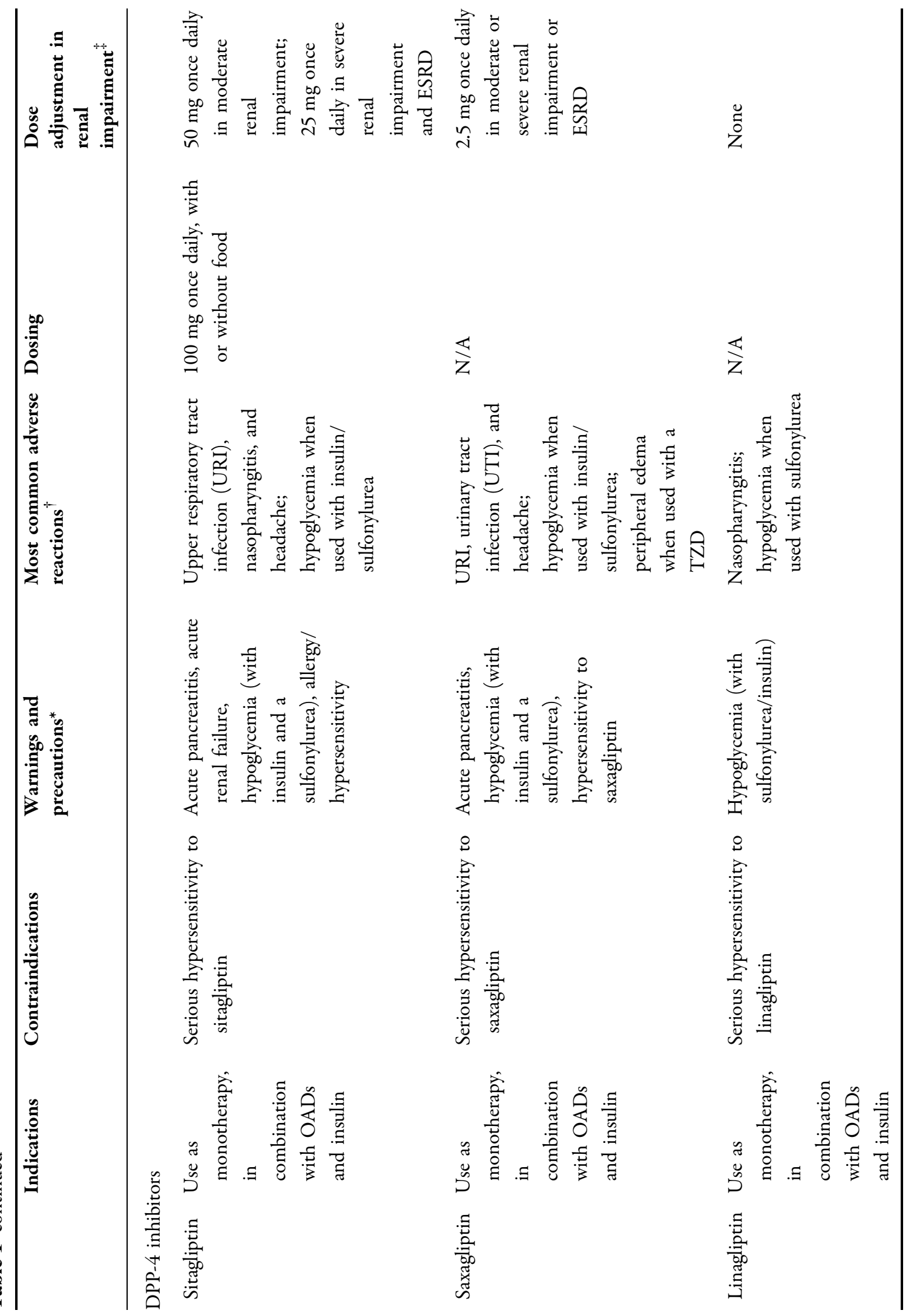




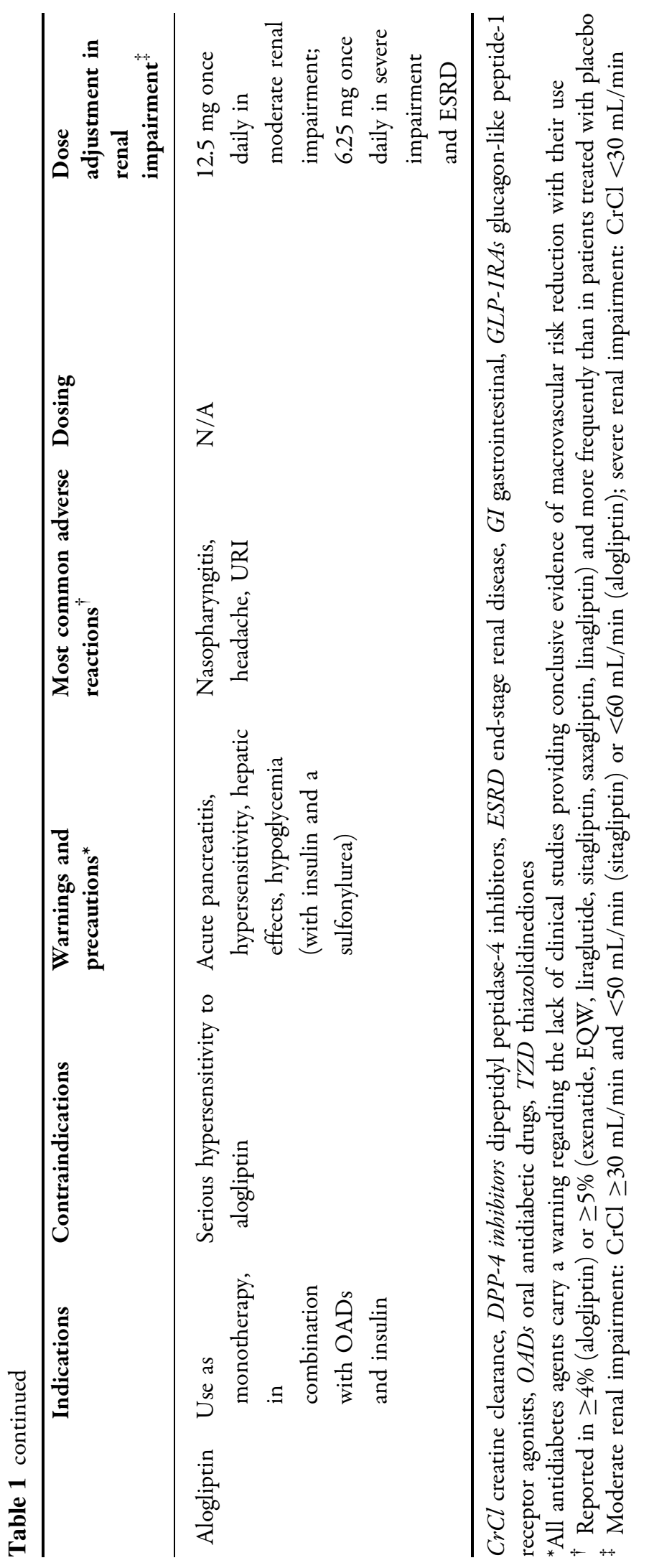




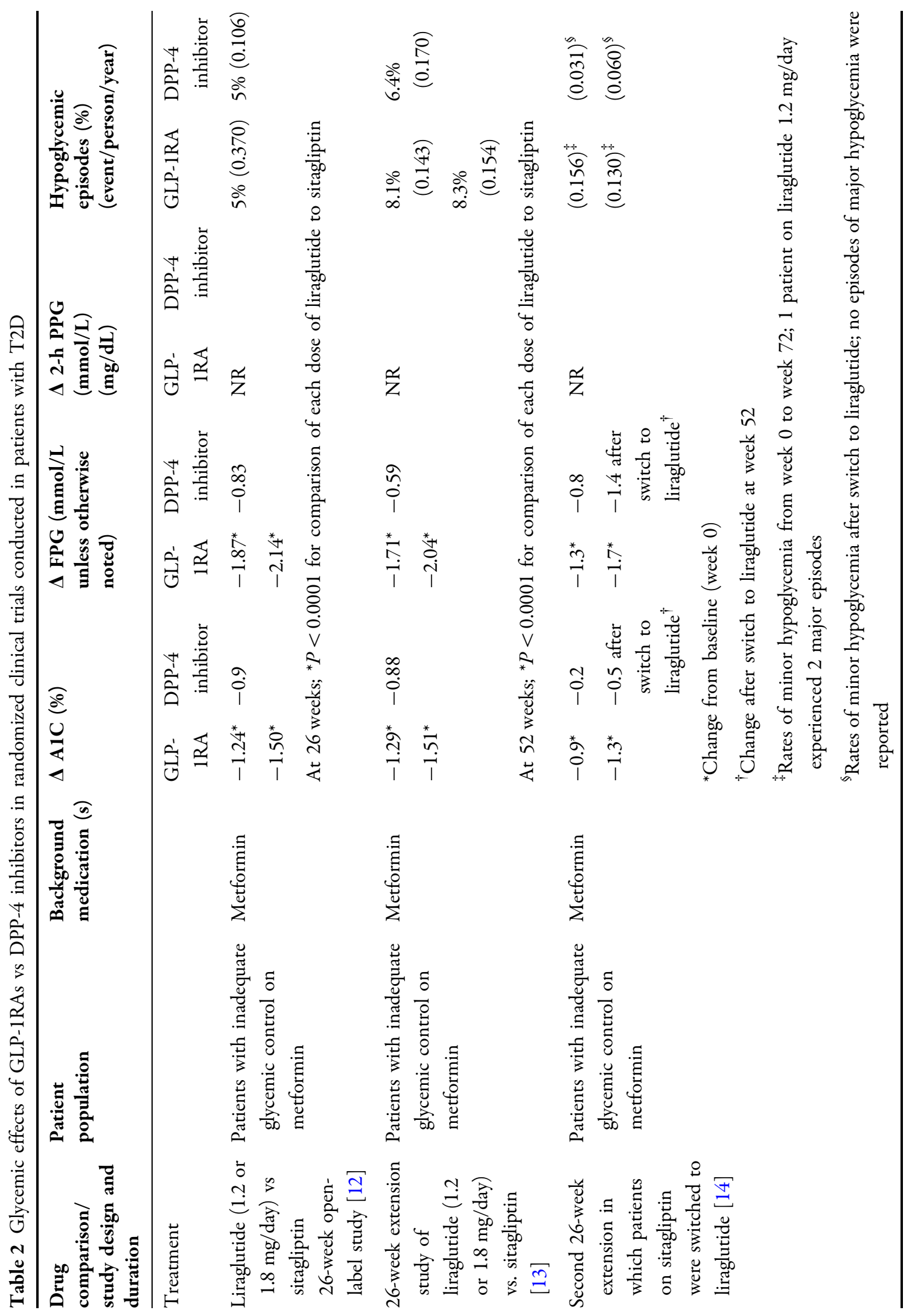




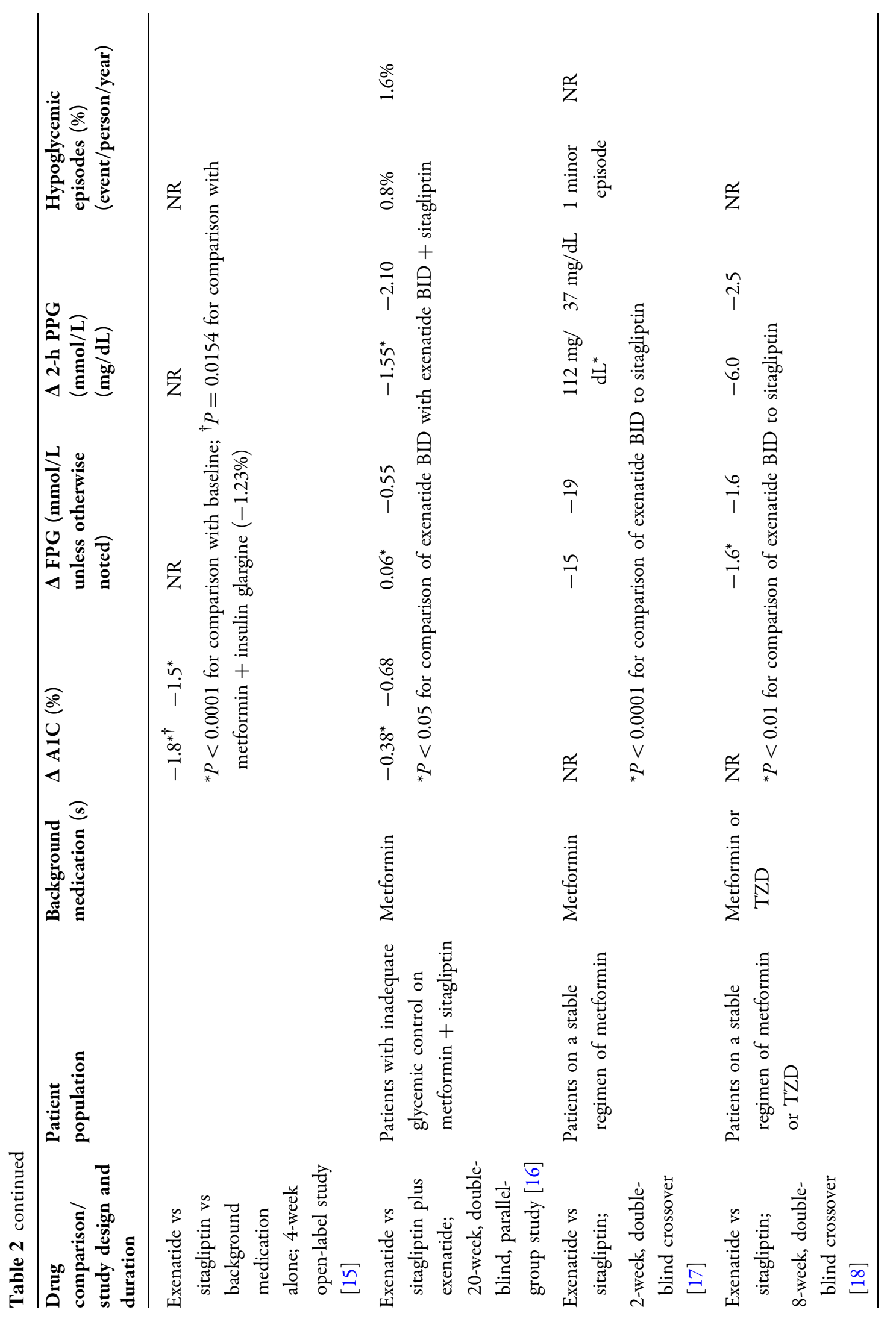




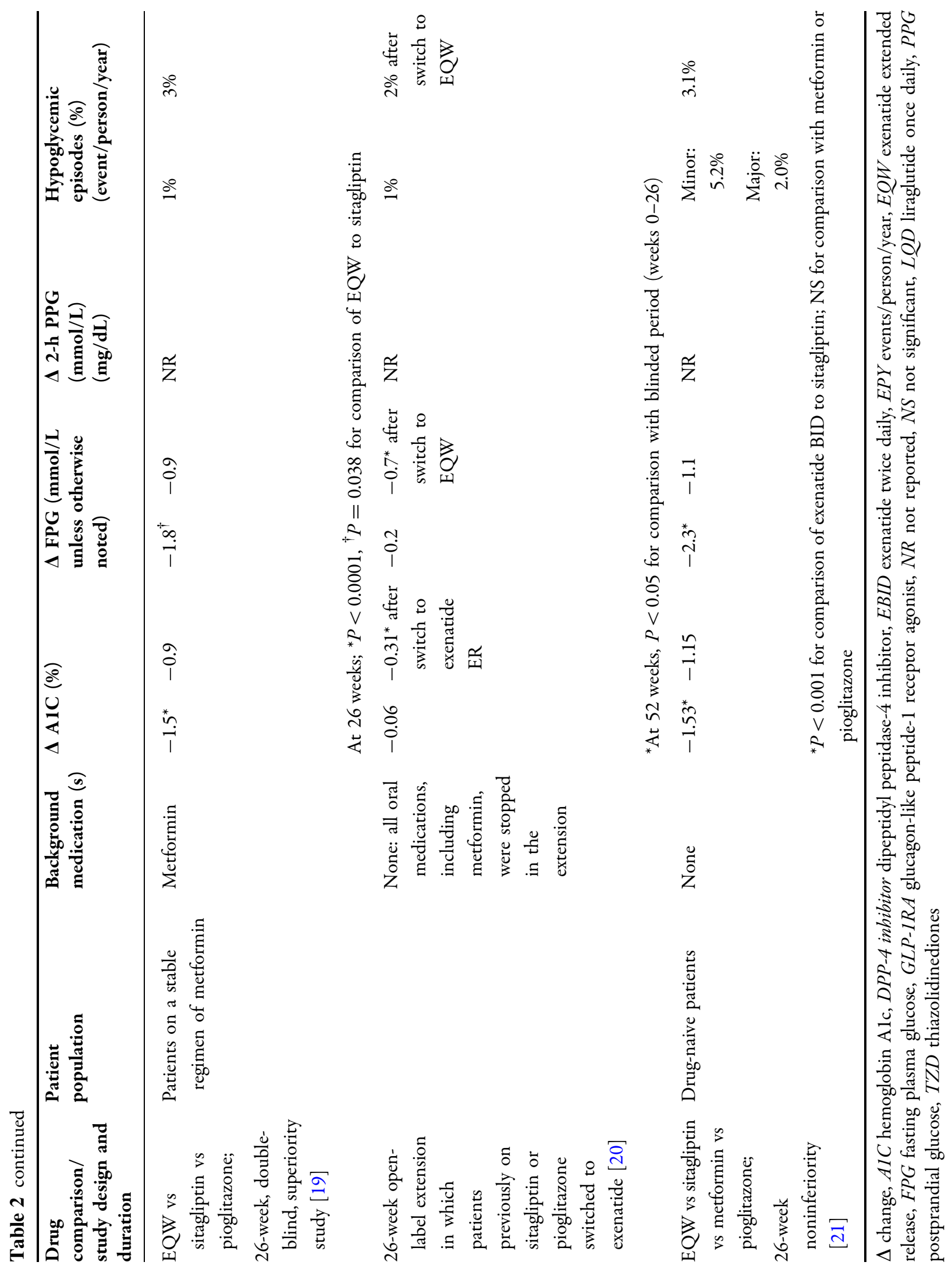




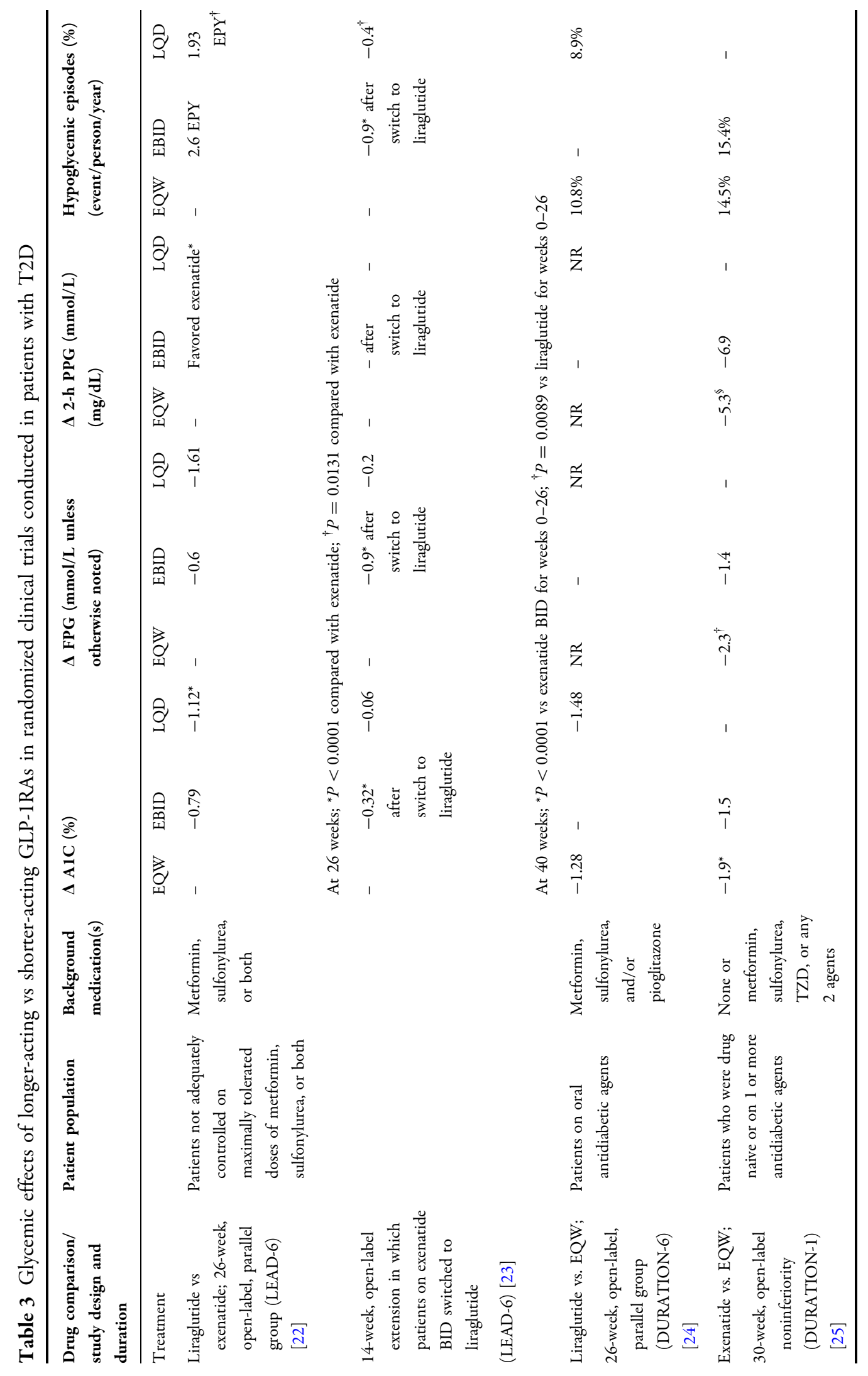




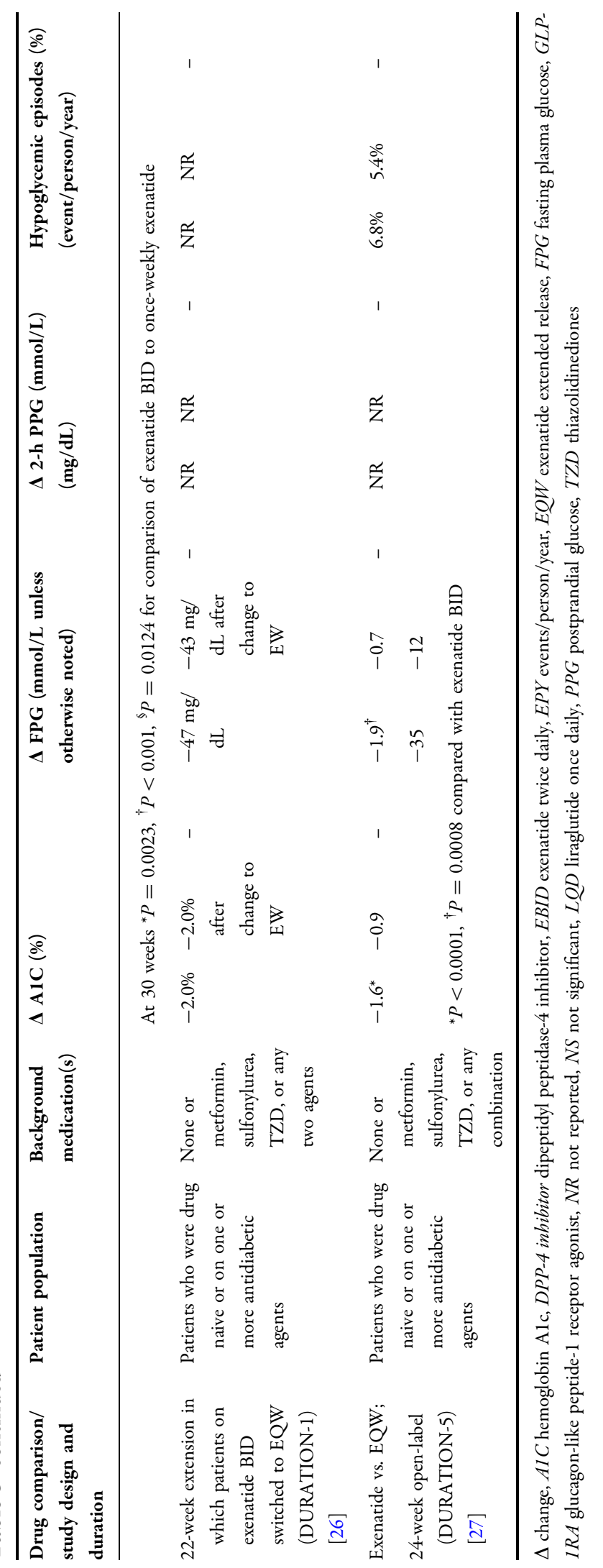




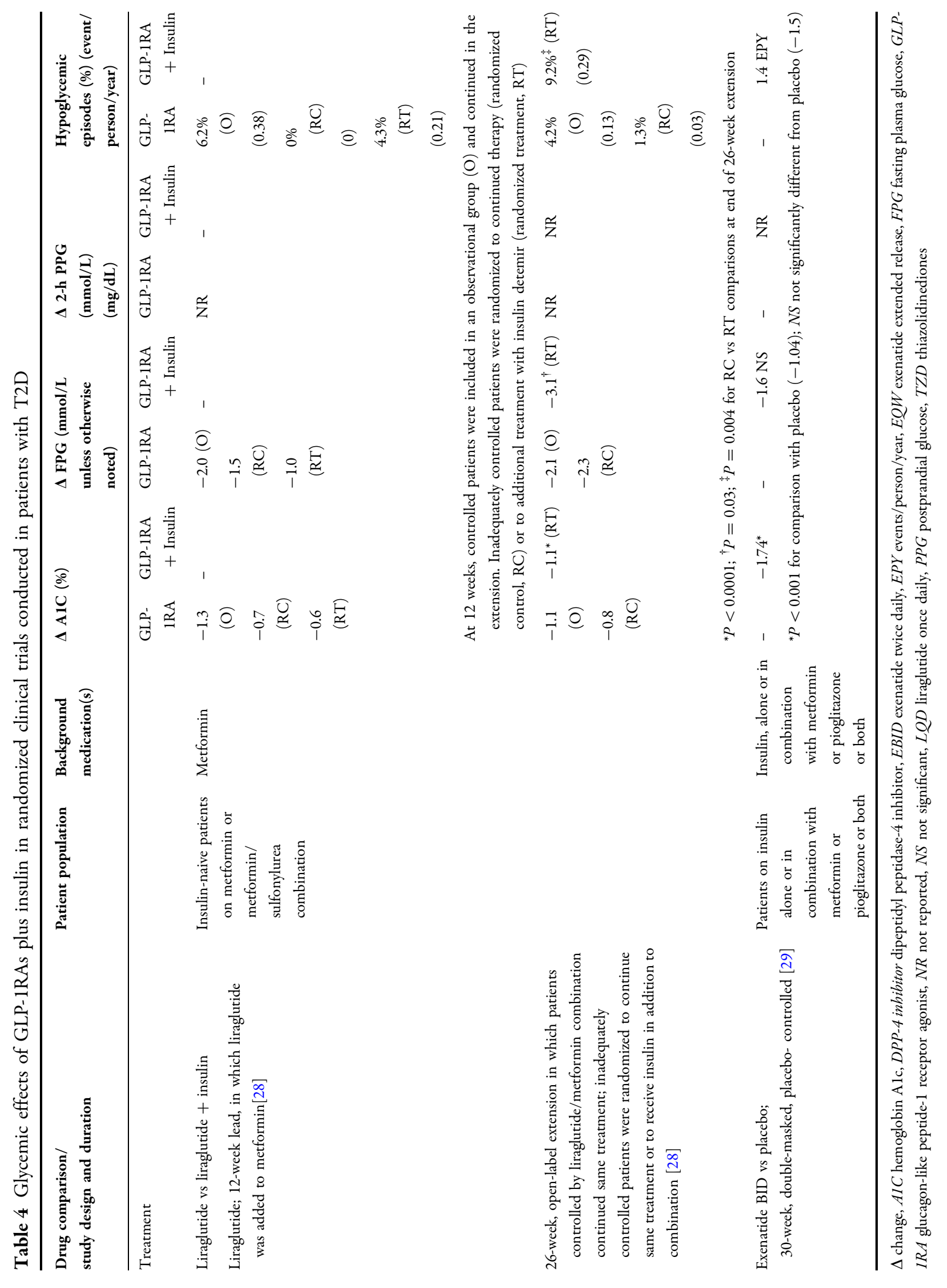




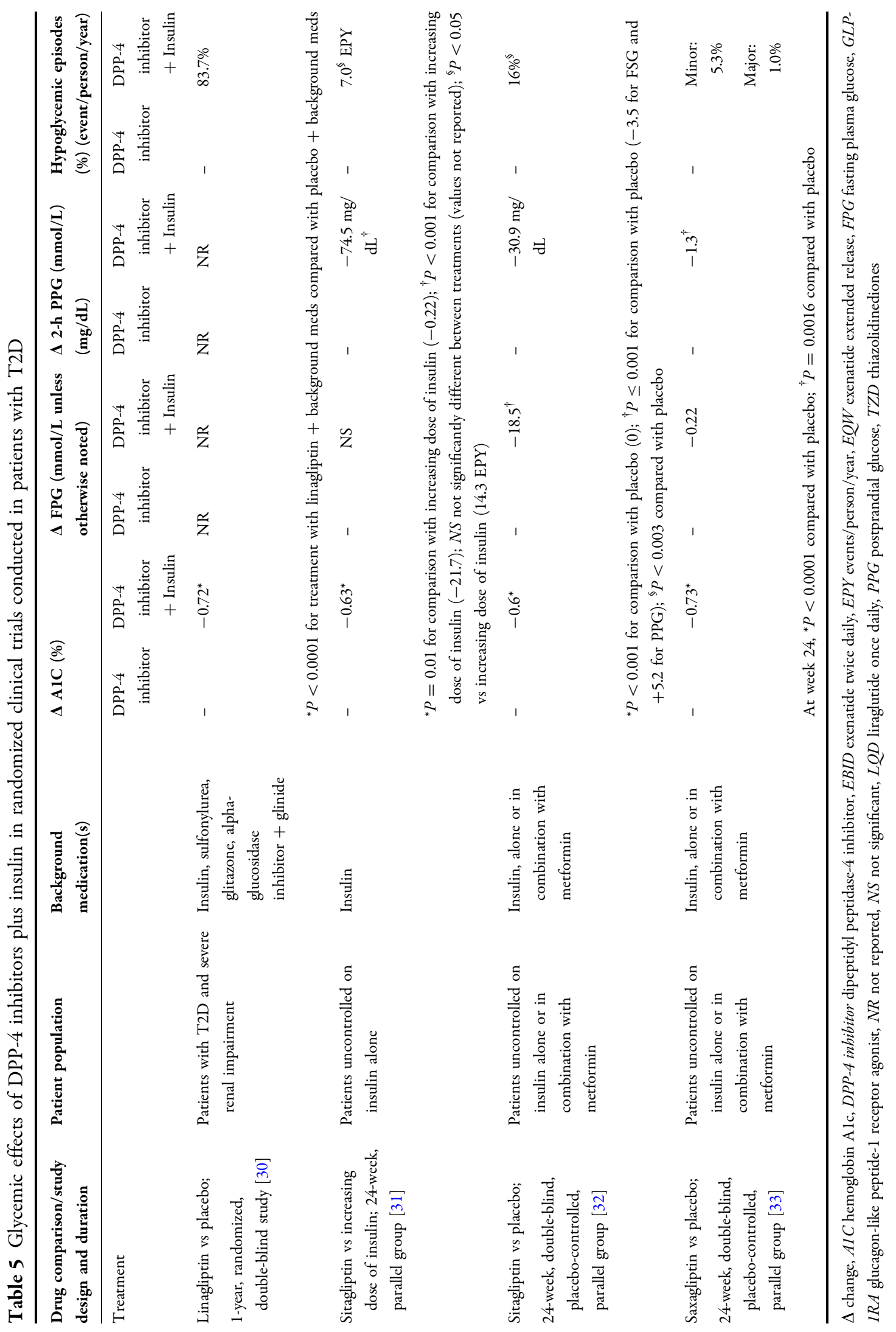




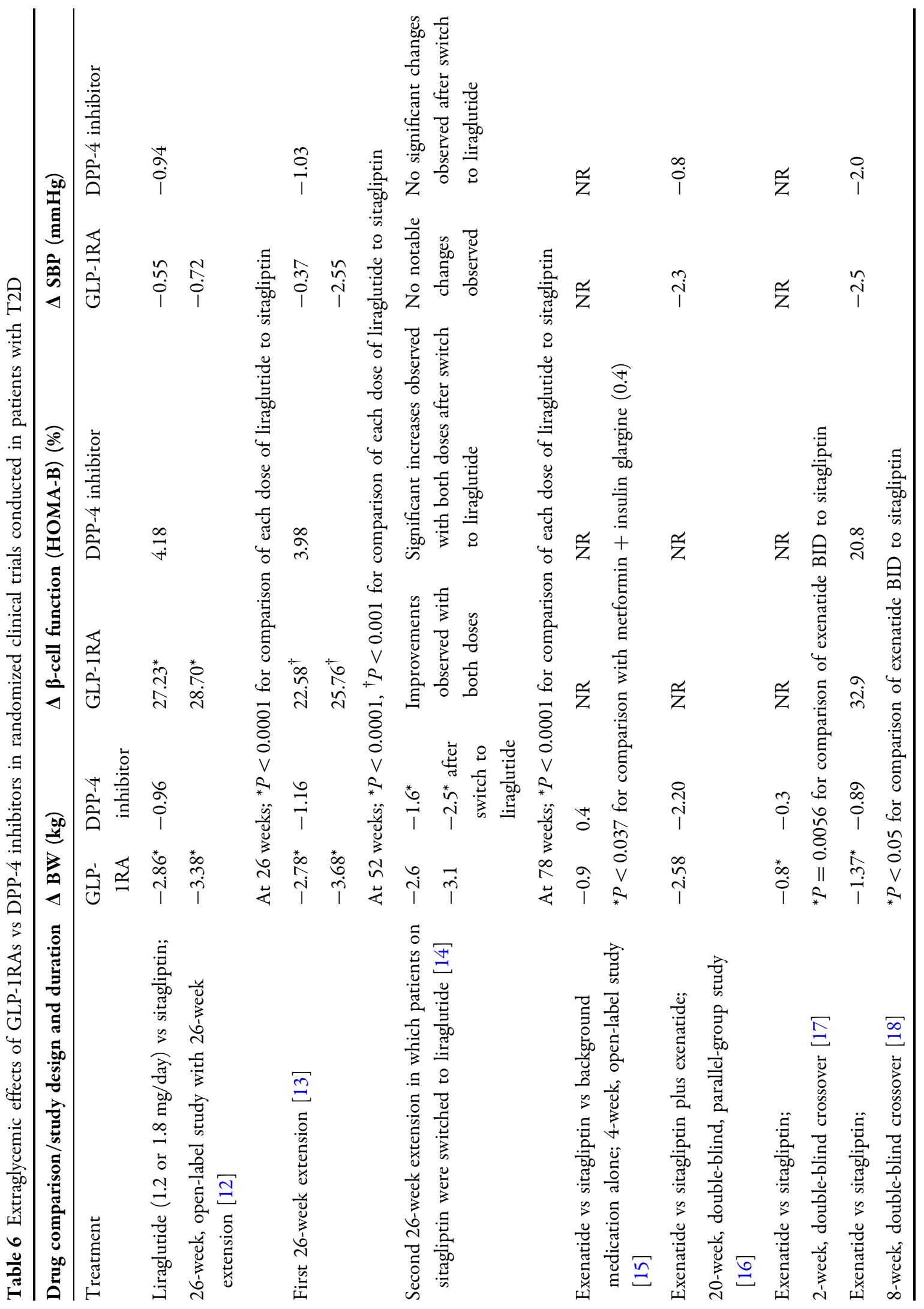




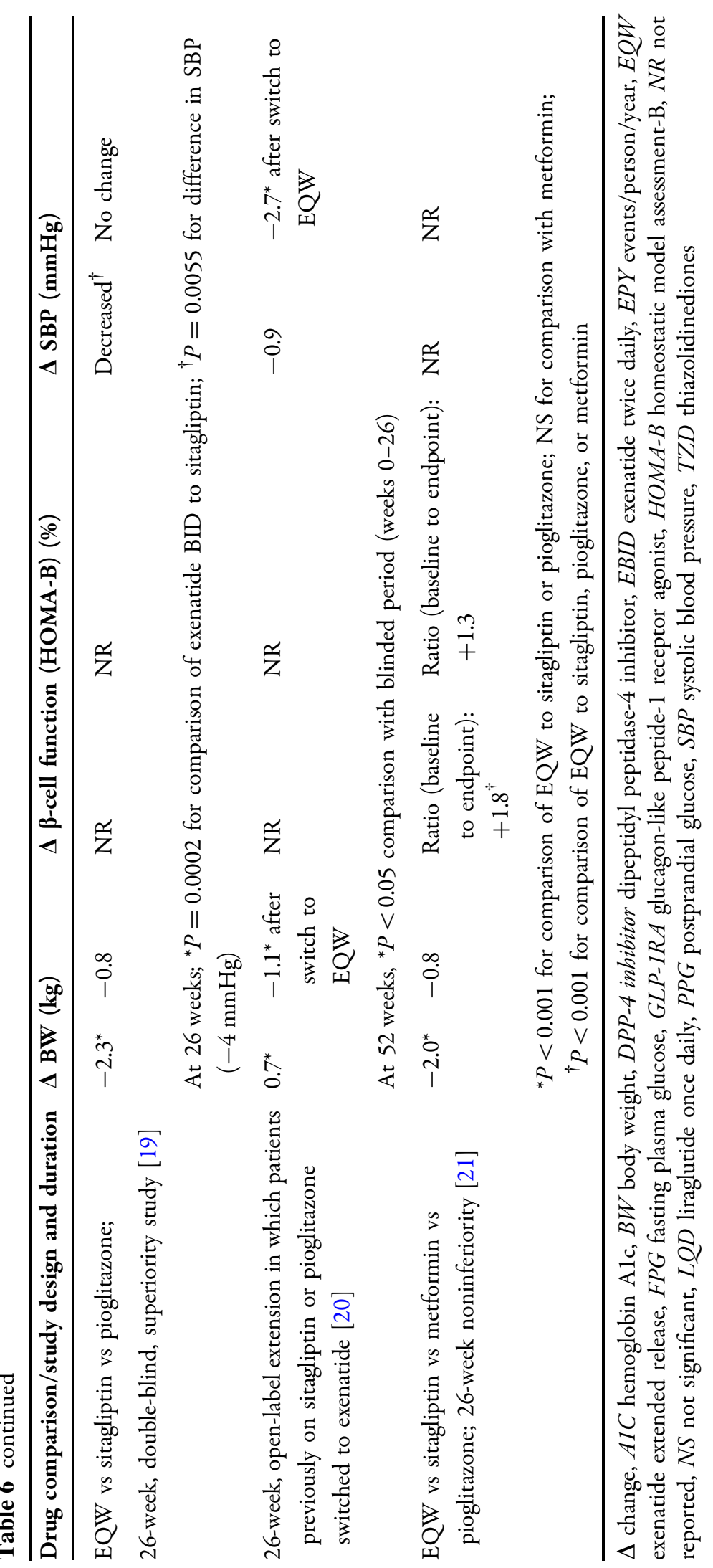




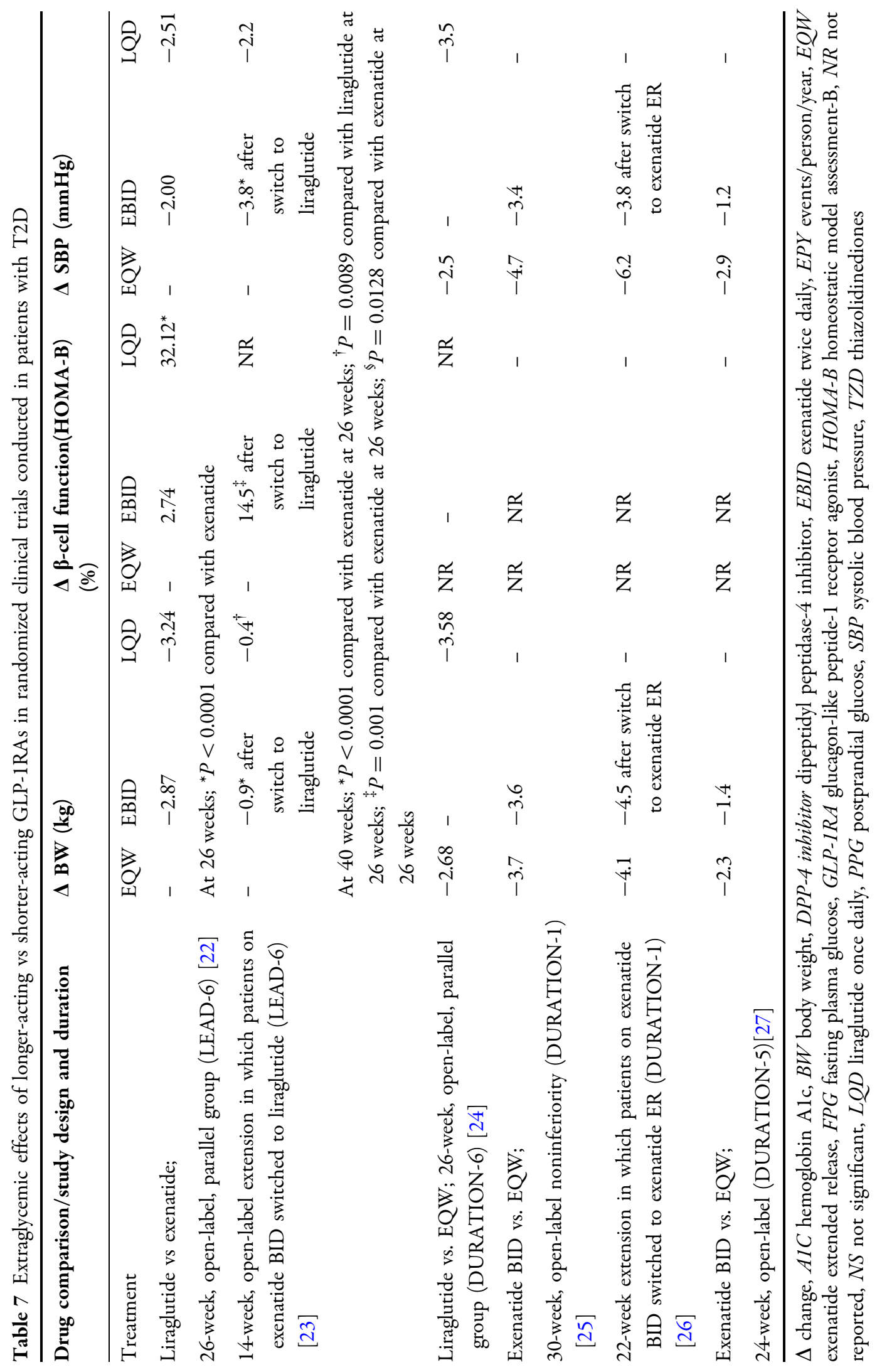




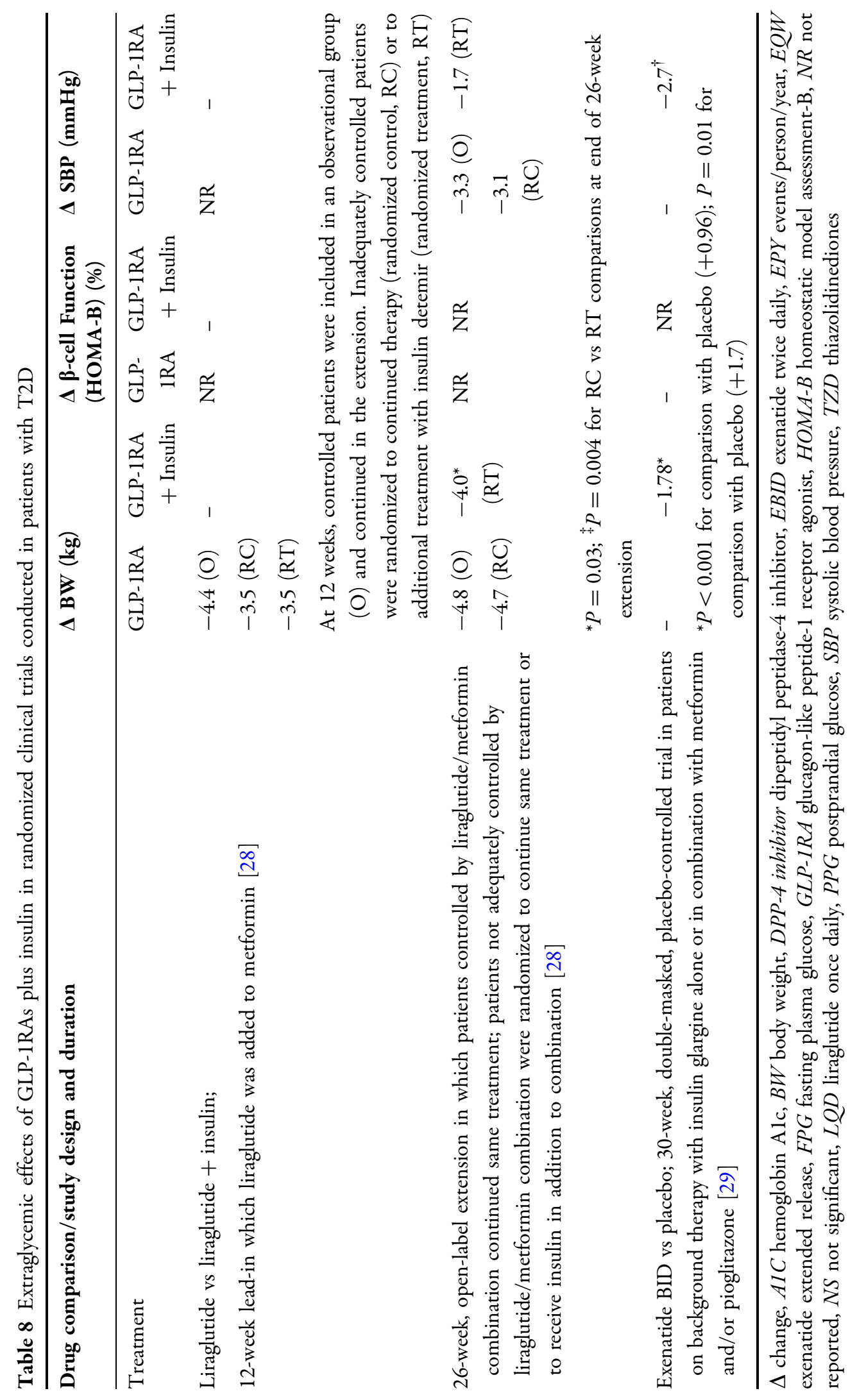




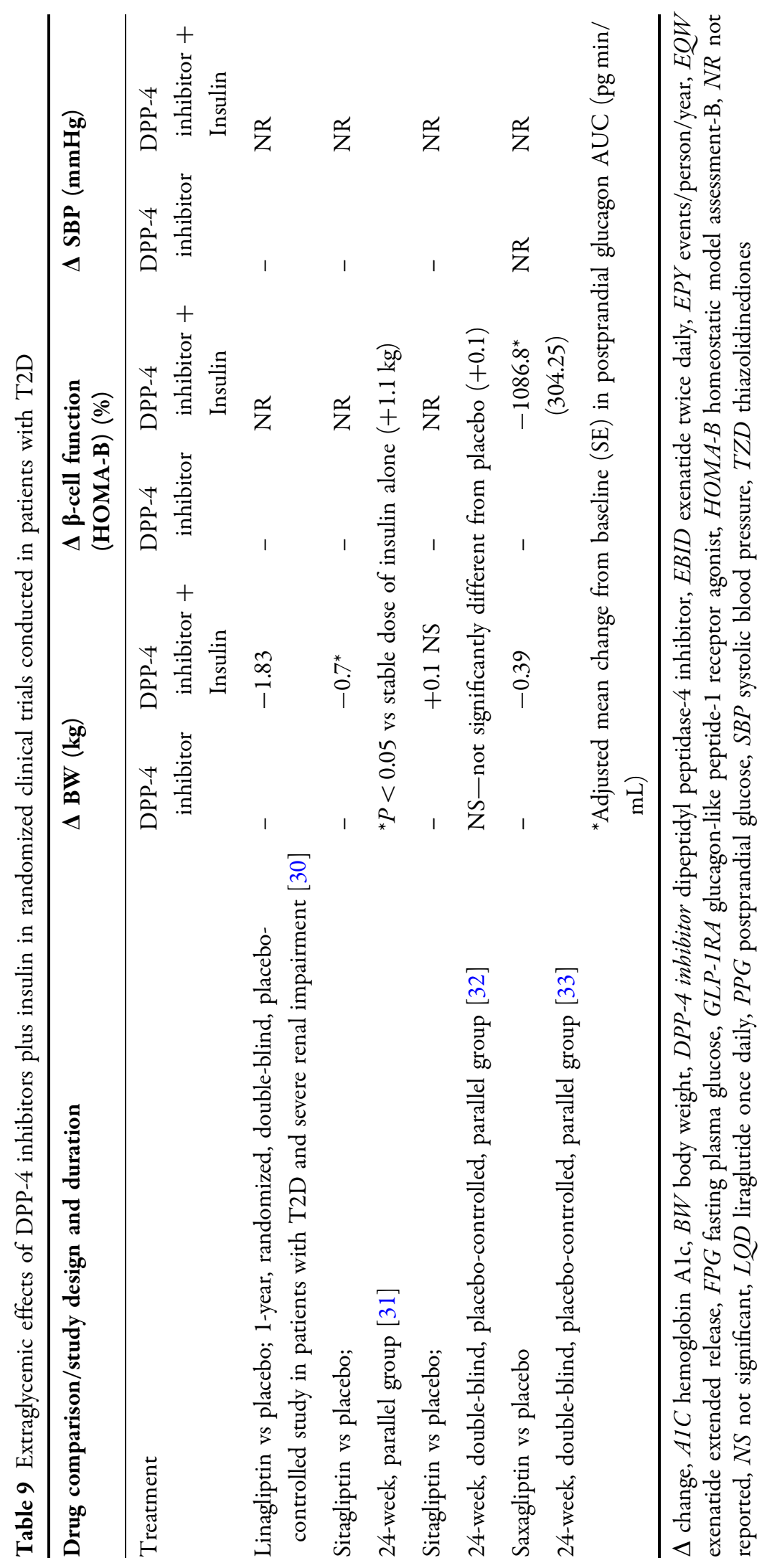


published between 2000 and 2012 and internal references on incretins and incretin-based therapies were considered. Specific search terms included glucagon-like peptide-1, GLP1RAs, exenatide, liraglutide, dipeptidyl peptidase 4, DPP-4 inhibitors, sitagliptin, saxagliptin, and linagliptin.

\section{Compliance with Ethics Guidelines}

The analysis in this article is based on previously conducted studies and does not involve any new studies of human or animal subjects performed by the author.

\section{ROLE OF INCRETIN THERAPIES IN DIABETES MANAGEMENT}

Guidelines currently include incretin therapies at all stages of pharmacologically treated T2D $[3,4]$. They are recommended for initial therapy (usually in combination with metformin and also as monotherapy in some patients), as addon therapy to oral agents, and even in combination with insulin with or without additional therapies $[3,4,50]$.

\section{NEWLY DIAGNOSED, TREATMENT- NAIVE PATIENTS}

Recommendations for the initial use of metformin in newly diagnosed patients are nearly universal, unless it is contraindicated. However, some patients with high hemoglobin $\mathrm{A}_{1 \mathrm{c}}$ (A1C) at diagnosis are unlikely to achieve their individualized glycemic goals on metformin alone and may require initial combination therapy, which should include classes of medications with complementary modes of action [4] to effectively target the underlying multiorgan pathophysiology of
T2D. Balancing adverse events (AEs) and treatment benefits, particularly the risk for hypoglycemia, is also important. One important option for initial combination therapy is metformin with a GLP-1RA or a DPP-4 inhibitor.

Data on initial combination therapy with GLP-1RAs and metformin in treatment-naive patients inadequately controlled on diet and exercise alone are limited, and no studies have compared initial combination therapy with metformin and GLP-1RAs or DPP-4 inhibitors. However, initial combination therapy with metformin and sitagliptin, saxagliptin, or linagliptin has been evaluated in several clinical trials [51-53]. In these trials, mean A1C reductions with initial combination therapy with a DPP-4 inhibitor and metformin $2,000 \mathrm{mg} /$ day ranged from 1.7 to $2.5 \%$. DPP-4 inhibitors were generally well tolerated in these trials. Rates of hypoglycemia were low and AEs occurred at a similar frequency across groups in each study.

GLP-1RAs and metformin as initial therapy have not been extensively evaluated, but GLP1RAs have been studied as add-on therapy to metformin in numerous trials. Results from these trials may provide some insight as to the potential effects of this combination as initial therapy. Such trials have demonstrated reductions in $\mathrm{A} 1 \mathrm{C}$ of $0.8-1.5 \%$, with weight loss of 2.3-2.8 kg [19, 54, 55]. Comparative data on the relative impact of incretin therapies among patients inadequately controlled on metformin will be considered later in the manuscript.

\section{Clinical Experience with Incretins as Initial Therapy}

In newly diagnosed patients requiring more than metformin to get to their individualized 


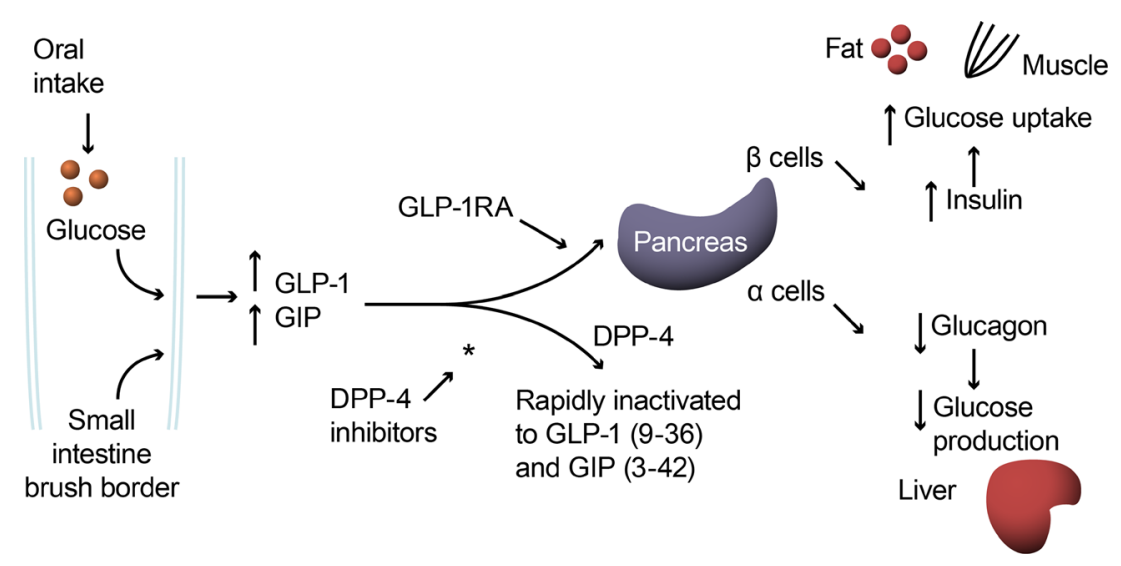

Fig. 1 Mechanism of Action of GLP-1RAs and DPP-4 inhibitors. DPP-4 inbibitors dipeptidyl peptidase- 4 inhibitors, GIP glucose-dependent insulinotropic

A1C goal, the choice for incretin therapy depends on several factors, including baseline A1C, body mass index, and comorbidities. GLP1RA plus metformin for obese patients with high A1C typically works well. It is possible to achieve glycemic targets in patients at A1C 10\% with GLP-1RAs and metformin [22]. In addition, the sustained weight loss associated with GLP-1RAs in clinical trials-which can be impressive in some patients-is beneficial to many organ systems [26]. Because of the limited glucose-lowering potential of DPP-4 inhibitors, metformin with a DPP-4 inhibitor in patients with baseline $\mathrm{A} 1 \mathrm{C} \geq 10 \%$ will not get most patients to their goal. Although there is evidence suggesting that DPP-4 inhibitors are less effective in patients with A1C $<8 \%$ [56], DPP-4 inhibitors can be used in patients with lower A1C when they are of normal weight, particularly when they resist injections.

For patients with high A1C, symptoms of hyperglycemia, and significant glucotoxicity, the use of insulin is recommended in current treatment guidelines. In the author's clinical experience, patients can be weaned off insulin, as glucotoxicity abates, and initiated on metformin and a GLP-1RA. While clinical data polypeptide, GLP-1 glucagon-like peptide-1. Reprinted with permission from McDougall et al [35]. Drugs for diabetes: part 5. DPP-4 inhibitors

on this approach are limited, it has been successful in the author's practice.

\section{INCRETIN AGENTS AS MONOTHERAPY}

There are some newly diagnosed patients in whom metformin is inappropriate or contraindicated. Incretin-based therapies may be a useful option in this population, which includes patients with moderate-to-severe renal impairment or heart failure.

However, patients with severe renal impairment or end-stage renal disease (ESRD) may also be poor candidates for some incretin therapies. Because they are cleared through the kidney, exenatide BID and EQW should not be used in this population [5, 7]. Although liraglutide is not cleared by renal mechanisms and no differences in safety and efficacy were found in patients with mild renal impairment in a meta-analysis of the Liraglutide Effect and Action in Diabetes (LEAD) clinical trial program [57], caution and careful monitoring should still be used when initiating liraglutide in such patients [7]. Sitagliptin, saxagliptin, and alogliptin, but not linagliptin, require dose 
reductions in patients with renal impairment or ESRD [8-11].

Although data from head-to-head studies of incretin therapies in drug-naive patients with T2D are relatively rare, and no studies have directly compared different DPP-4 inhibitors, the limited comparisons between GLP1-RAs and DPP-4 inhibitors and between various GLP-1RAs can help guide the physician in their choice of incretin therapy, if metformin is not an option.

Data from RCTs comparing EQW with sitagliptin monotherapy showed significantly greater reductions in FPG, A1C, and body weight, and showed that a significantly higher proportion of patients achieved a target A1C level of $<7.0 \%$ or $\leq 6.5 \%$, with EQW. Moreover, there were no significant differences between EQW and metformin monotherapy on reductions in FPG or $\mathrm{A} 1 \mathrm{C}$ or on the proportion of patients achieving a target A1C level of $<7.0 \%$ [21], suggesting similar outcomes.

Among patients who managed their diabetes with diet and exercise alone, EQW provided significantly greater reduction in A1C, FPG, and weight compared with exenatide BID. A significantly higher proportion of patients achieved target A1C levels of $<7.0 \%$ and $\leq 6.5 \%$ with EQW [27]. Few head-to-head data on the use of liraglutide compared with other incretin agents in treatment-naive patients are available. However, patients treated with liraglutide monotherapy showed significantly greater reductions in A1C from baseline, compared with glimepiride $[58,59]$.

\section{Clinical Experience with Incretins in Monotherapy}

Although prescribing information for liraglutide or EQW advises against using these agents as first-line therapy, they are typically my preferred alternative to metformin if metformin cannot be used. GLP-1RAs may be particularly suitable because they are effective, may facilitate weight loss, and are associated with a low risk of hypoglycemia. When considering GLP-1RAs, the author's patients usually receive the longer-acting GLP-1RAs, liraglutide and EQW, instead of exenatide BID, because they are dosed less frequently and have a superior effect on fasting glucose [22, 27].

In patients with moderate-to-severe renal impairment who require $\mathrm{A} 1 \mathrm{C}$ reductions $>1 \%$ or who would benefit from weight loss, liraglutide is preferred because exenatide BID and EQW should not be used in such patients, but it should be used with caution [5-7]. Linagliptin or reduced-dose sitagliptin or saxagliptin is each a useful option in nonobese patients and/or if a patient with renal insufficiency requires $\leq 1 \%$ A1C reduction [60]. DPP-4 inhibitors may be particularly appropriate as initial therapy in frail or slim elderly patients with renal impairment, moderately elevated A1C, and elevated PPG without a substantially elevated FPG [60].

Incretins, including GLP-1RAs, are also useful in patients who cannot tolerate the gastrointestinal (GI) side effects of metformin. In the author's experience, GI symptoms with GLP-1RAs are self-limiting and disappear over time, unlike the GI symptoms often observed with metformin. In elderly patients with severe anorexia with metformin monotherapy, monotherapy with a DPP-4 inhibitor is an important option.

Sulfonylureas may also be an option for patients who refuse incretin therapy, but their potential adverse effects on $\beta$-cells [61], elevated risk of hypoglycemia, tendency toward weight gain $[3,4]$, and limited effectiveness over time should be considered carefully [62]. Compared 
with sulfonylureas, monotherapy studies with incretin-based therapies demonstrate better safety, and in the case of GLP-1RAs, better efficacy $[63,64]$.

Similarly, the author tends to choose incretins over thiazolidinediones (TZDs) in many patients because of the potential adverse effects of TZDs, including weight gain, peripheral edema, and increased risk of congestive heart failure [3].

\section{INCRETINS AS ADD-ON THERAPY}

Use of incretins in dual therapy may be considered after lifestyle and drug monotherapy become insufficient and before $\beta$-cell function ceases and insulin therapy becomes the only option.

\section{Incretin Plus Metformin Therapy}

In head-to-head studies comparing GLP1-RAs with DPP-4 inhibitors, incretin-based therapies have demonstrated modest to robust effects on glycemic indices in patients on metformin, with greater reductions in FPG and A1C with GLP1RAs, compared with DPP-4 inhibitors. For example, in a head-to-head comparison of EQW with sitagliptin, in which each was used as add-on therapy to metformin, A1C reduction was significantly greater with EQW, overall, as well as among patients with A1C levels $\geq 9 \%$ [19]. Similarly, in a head-to-head comparison of liraglutide and sitagliptin in patients with inadequate control on metformin, liraglutide was associated with significantly greater reductions in A1C, FPG, and body weight with a similar incidence of hypoglycemia $[12,13]$. In both trials, nausea and vomiting were more common with GLP-1RAs than sitagliptin $[12,13,19]$.
Two studies have also compared the efficacy of liraglutide to exenatide BID [22] and EQW [24] in patients inadequately controlled on metformin, sulfonylurea, or both (in the exenatide BID trial) or metformin, sulfonylurea, and/or pioglitazone (in the EQW trial). In the first trial, liraglutide provided significantly greater improvements in A1C $(1.1 \%$ vs $0.8 \%, P<0.0001)$ than EQW [22]. While both agents were well tolerated, nausea was less persistent and hypoglycemia less frequent with liraglutide than with exenatide BID. When compared with EQW, liraglutide was associated with greater reductions in A1C $(1.48 \%$ vs $1.28 \%)$ and body weight (3.6 vs $2.7 \mathrm{~kg}$ ); however, EQW was associated with less nausea and vomiting [24]. Reductions in systolic BP (SBP) were also similar between groups.

Blood pressure management is an important component of treatment in all patients with T2D [65]. Liraglutide, exenatide BID, EQW, and sitagliptin generally show similar reductions in SBP, while diastolic BP is not affected [12-14, 22, 24, 25]. One study of EQW showed greater reduction in SBP compared with sitagliptin [19]. While BP reductions are generally beneficial and cardiovascular risk reduction is a priority in diabetes management, the author uses incretin therapies in their practice for their glycemic and weight effects and not their impact on BP.

\section{Clinical Experience with Incretins as Add-on Therapy to Metformin}

The use of incretin therapy as add-on therapy with metformin is recommended in treatment guidelines and it is the author's primary intervention in most patients on metformin whose A1C is above their target goal $[3,4]$. The 
greater A1C reduction and weight loss associated with GLP-1RAs make them my preferred incretin therapy in most patients. Most of the author's patients lose approximately $3-4.5 \mathrm{~kg}$ on GLP-1RAs, but some may experience more dramatic weight reductions of up to $13-18 \mathrm{~kg}$.

In fact, the need for weight loss may drive the choice of GLP1-RAs over DPP-4 inhibitors in some patients, and may persuade patients to choose injections over oral therapy. Moreover, DPP-4 inhibitors are postprandial modulators that may be less useful than longer-acting GLP1-RAs in patients with FPG $>200 \mathrm{mg} / \mathrm{dL}$. When the injection barrier is insurmountable, DPP-4 inhibitors can be prescribed; however, patients should be actively involved in the decision-making process. In nonobese patients requiring $<1 \%$ reduction in $\mathrm{A} 1 \mathrm{C}$, a DPP-4 inhibitor can be used if the patient prefers. However, the author usually switches patients already on DPP-4 inhibitors to GLP-1RAs if they require an additional $0.5 \% \mathrm{~A} 1 \mathrm{C}$ reduction.

Head-to-head clinical trials demonstrate that the more protracted agents have fewer GI symptoms, with exenatide BID causing the most GI symptoms, followed by liraglutide, and then EQW [22, 24, 25]. In the author's experience, many patients who did not tolerate exenatide BID are able to successfully use liraglutide and EQW.

Before initiating any GLP-1RA, patients should be informed of the potential for GI AEs. To mitigate symptoms with exenatide and liraglutide, treatment should be initiated at a lower dose and titrated up to achieve maximal effect. For example, if patients experience nausea with liraglutide, the dose is increased only when the nausea is resolved. In the rare event that nausea remains an issue, the titration of the liraglutide dose can be slowed. This technique has been found to be effective, even though it is not specifically recommended in the labeling [7]. EQW is not usually titrated, but the author's patients with nausea on exenatide BID do not use the 10-mcg dose until the nausea abates.

\section{Incretin Plus Sulfonylurea Therapy}

Both sulfonylureas and incretins stimulate release of insulin from pancreatic $\beta$-cells [34, 66]. Insulin release by sulfonylureas is glucose independent (primarily affects FPG) and increases the risk for hypoglycemia. Conversely, incretins stimulate insulin in a glucose-dependent manner, minimizing risk of hypoglycemia. Therefore, combining incretin therapy with a sulfonylurea potentially allows for lowering of the sulfonylurea dose and a possible reduction in the risk of hypoglycemia, while maintaining or increasing glycemic control [5-7, 67]. While results from clinical trials indicate that adding an incretin to a sulfonylurea reduces A1C by $0.5-1.1 \%[64,67$, 68], there are few data on the comparative impact of incretin agents in patients inadequately controlled on sulfonylureas alone.

In patients already using sulfonylureas who need an $\mathrm{A} 1 \mathrm{C}$ reduction of $1-1.5 \%$, the dose of sulfonylurea should be reduced when DPP-4 inhibitors or GLP-1RAs are added. However, the current sulfonylurea dose should be maintained if an $\mathrm{A} 1 \mathrm{C}$ reduction of $>1.5 \%$ is needed. The author also asks patients receiving sulfonylurea therapy in combination with an incretin for an extra fingerstick glucose measurement before dinner.

\section{USE OF INCRETINS IN TRIPLE THERAPY}

While guidelines often recommend insulin therapy as the preferred option for patients 
inadequately controlled on metformin and an additional agent, many patients receive triple therapy at this stage, particularly if they are reluctant to initiate insulin.

\section{Incretin Plus Metformin and Sulfonylurea}

Although several studies have evaluated the use of incretin therapy in combination with metformin and a sulfonylurea, there have been no such head-to-head comparisons. In one study, liraglutide added to metformin and a sulfonylurea reduced A1C by $1.3 \%$ and decreased weight by $1.8 \mathrm{~kg}$ [69]. A similar study of exenatide BID reported a reduction in $\mathrm{A} 1 \mathrm{C}$ of $1.0 \%$ and a weight loss of $2.5 \%$ [70]. In these trials, hypoglycemia was reported by $27 \%$ [69] of patients on liraglutide and $27 \%$ of patients on exenatide [70]. In a study evaluating sitagliptin in combination with metformin and a sulfonylurea, the combination reduced A1C by $0.9 \%$ but increased weight by $0.8 \mathrm{~kg}$ [71]. The incidence of hypoglycemia with the sitagliptin combination was $16.4 \%$.

The combination of metformin, sulfonylurea, and a GLP-1RA is the author's preferred noninsulin-based triple therapy, because this combination is effective in reducing A1C and FPG with few hypoglycemic events. To avoid hypoglycemia when using this combination, the sulfonylurea dose typically should be reduced when adding an incretin therapy.

\section{Incretin Plus Metformin and TZD Therapy}

Adding GLP-1RA to TZD therapy for patients inadequately controlled with TZD and metformin leads to complementary effects: an increase in $\beta$-cell insulin secretory function (GLP-1RAs), inhibition of glucose production by the liver (metformin), and an increase in glucose uptake by muscle (TZD), and consequently, improved glycemic control [72]. Combining incretins with TZDs may also mitigate the adverse effect of TZDs on weight. Data on the comparative use of incretin therapies with TZDs and metformin are limited. However, a study of liraglutide with metformin and a TZD reported a reduction in A1C of $1.5 \%$ with a reduction in weight of $1-2 \mathrm{~kg}$ and an incidence of hypoglycemia of 7.9-9.0\% [73].

\section{INCRETIN PLUS INSULIN THERAPY}

In many patients, addition of insulin to oral antidiabetic drugs (OADs) or GLP-1RAs is required to meet treatment goals. New studies demonstrate the utility of combining basal insulin with incretin therapies. When used in combination with GLP-1RAs or DPP-4 inhibitors, exogenous insulin is augmented with endogenous, glucose-dependent insulin secretion, allowing the body to compensate for increased carbohydrate intake without increasing the dose of exogenous insulin and, consequently, risk of hypoglycemia [28, 31-33]. Complementary combination therapy can be accomplished by adding a short-acting incretin agent (exenatide) that primarily targets PPG to basal insulin that primarily targets FPG [29].

Longer-acting liraglutide in combination with basal insulin has also shown to improve glycemic indices. Liraglutide targets both FPG and PPG, without the increase in hypoglycemia or weight gain associated with increased insulin dosing. Addition of GLP-1RAs allows for lowering the basal insulin dose and may even eliminate the need for prandial insulin $[15,29]$. In fact, insulin doses should be reduced when initiating GLP-1RAs in patients on insulin. With DPP-4 inhibitors, the basal insulin dose stays 
the same since FPG changes are minimal [31-33]. Incretin therapies are useful in patients taking insulin, even if only to prevent the intensification of basal insulin regimens to multiple daily injections.

\section{LONG-TERM SAFETY OF INCRETIN THERAPIES}

\section{Pancreatitis}

Pancreatitis has been reported in postmarketing surveillance for both GLP-1RAs and DPP-4 inhibitors [74]. In patients with risk factors for pancreatitis, including gallstones, high triglycerides, or excessive alcohol intake, incretins should be used with caution. Liraglutide, exenatide BID, and EQW are not recommended in patients with a history of pancreatitis [5-7]. Before initiating incretin therapy, the possible risk for pancreatitis with patients should be discussed. Patients should be advised to contact their health care provider immediately if they experience severe abdominal pain. While careful observation for signs and symptoms of pancreatitis is recommended following incretin initiation, the totality of clinical, preclinical, and postmarketing evidence does not clearly substantiate an association between incretin therapies and acute pancreatitis, although published opinions on this topic differ [75-77]. The author has had no experience with pancreatitis in patients using incretin therapy. Moreover, experts convened by the National Institute of Diabetes and Digestive and Kidney Diseases in June 2013 concluded that there is likely no increased risk for pancreatic cancer associated with incretin therapies, although longer-term studies are needed [78].

\section{Thyroid Neoplasm}

Based on preclinical data, liraglutide and exenatide BID are absolutely contraindicated in patients with a personal or family history of medullary thyroid carcinoma and in patients with multiple endocrine neoplasia syndrome type $2[6,7]$. Although rare (the author has seen medullary thyroid carcinoma three times in 25 years), the author recommends palpating the patient's thyroid gland to examine for nodules before starting therapy.

\section{CONCLUSION}

Incretins play an important role in normal glucose homeostasis, and incretin therapies should be considered in combination treatment regimens for patients with T2D from early onset to late disease. The selection of a particular agent should be individualized and depends on patient characteristics, preferences, and treatment goals, as well as differences in overall clinical profiles among incretin agents.

In clinical trials and in my own clinical experience, GLP-1RAs have shown greater and sustained glycemic control compared with DPP4 inhibitors, with the additional benefits of weight loss and reduced SBP. High patient satisfaction has been reported with GLP-1RAs despite the subcutaneous route of administration [38, 79-81]. In combination therapy with insulin, GLP-1RAs lead to sustained glycemic control, along with reduced insulin doses without increase in hypoglycemia or weight gain.

As a whole, the incretin class of antidiabetes agents is very useful, and both DPP-4 inhibitors and GLP-1RAs have improved T2D management. Many patients now consider 
injectable therapy in view of the observed benefits of GLP-1RAs and those who succeed with this therapy are satisfied with the results.

\section{ACKNOWLEDGMENTS}

The author wishes to thank Nicole Cooper and Heba Costandy of MedVal Scientific Information Services, LLC, for providing medical writing and editorial assistance. This manuscript was prepared according to the International Society for Medical Publication Professionals' "Good Publication Practice for Communicating Company-Sponsored Medical Research: the GPP2 Guidelines". Funding to support the preparation of this manuscript and article processing charges was provided by Novo Nordisk Inc. Dr. Tibaldi is the guarantor for this article and takes responsibility for the integrity of the work as a whole, from inception to published article.

Conflict of interest. The author is a consultant and speakers bureau member for Novo Nordisk; is a speakers bureau member for Daiichi and Merck; has received payment for lectures from Eli Lilly and sanofi-aventis; has participated in nonpromotional CME activities sponsored by Eli Lily, Novo Nordisk, and sanofiaventis; and has received payment for the development of educational programs for Eli Lilly, Novo Nordisk, and sanofi-aventis. He has participated in 2 Pri-Med programs, 1 for Eli Lilly and 1 for Novo Nordisk, and has developed and presented continuing education programs for the American Association of Diabetes Educators, sponsored by sanofi-aventis. The author has indicated that he has no other conflicts of interest regarding the content of the article.
Compliance with ethics guidelines. The analysis in this article is based on previously conducted studies, and does not involve any new studies of human or animal subjects performed by the author.

Open Access. This article is distributed under the terms of the Creative Commons Attribution Noncommercial License which permits any noncommercial use, distribution, and reproduction in any medium, provided the original author(s) and the source are credited.

\section{REFERENCES}

1. Nauck MA. Unraveling the science of incretin biology. Am J Med. 2009;122:S3-10.

2. Woerle HJ, Carneiro L, Derani A, Goke B, Schirra J. The role of endogenous incretin secretion as amplifier of glucose-stimulated insulin secretion in healthy subjects and patients with type 2 diabetes. Diabetes. 2012;61:2349-58.

3. Inzucchi SE, Bergenstal RM, Buse JB, et al. Management of hyperglycemia in type 2 diabetes: a patient-centered approach. Position statement of the American Diabetes Association (ADA) and the European Association for the Study of Diabetes (EASD). Diabetes Care. 2012;35:1364-79.

4. Rodbard HW, Jellinger PS, Davidson JA, et al. Statement by an American Association of Clinical Endocrinologists/American College of Endocrinology consensus panel on type 2 diabetes mellitus: an algorithm for glycemic control. Endocr Pract. 2009; 15:540-59.

5. Byetta $^{\circledR} \quad$ (exenatide) injection [prescribing information]. Princeton: Bristol-Myers Squibb Company; 2011.

6. Bydureon ${ }^{\circledR} \quad$ (exenatide extended-release for injectable suspension) [prescribing information]. Princeton: Bristol-Myers Squibb Company; 2012.

7. Victoza $^{\circledR}$ liraglutide (rDNA origin) injection [prescribing information]. Princeton: Novo Nordisk Inc.; 2013.

8. Januvia $^{\circledR} \quad$ (sitagliptin) tablets [prescribing information]. Whitehouse Station: Merck \& Co., Inc.; 2012. 
9. Onglyza ${ }^{\circledR} \quad$ (saxagliptin) tablets [prescribing information]. Princeton: Bristol-Myers Squibb Company; 2011.

10. Nesina ${ }^{\circledR}$ (alogliptin) tablets [prescribing information]. Takeda Pharmaceuticals America, Inc.; 2013.

11. Tradjenta ${ }^{\circledR}$ (linagliptin) [prescribing information]. Ridgefield: Boehringer Ingelheim Pharmaceuticals, Inc.; 2012.

12. Pratley RE, Nauck M, Bailey T, et al. Liraglutide versus sitagliptin for patients with type 2 diabetes who did not have adequate glycaemic control with metformin: a 26-week, randomised, parallel-group, open-label trial. Lancet. 2010;375:1447-56.

13. Pratley R, Nauck M, Bailey $T$, et al. One year of liraglutide treatment offers sustained and more effective glycaemic control and weight reduction compared with sitagliptin, both in combination with metformin, in patients with type 2 diabetes: a randomised, parallel-group, open-label trial. Int J Clin Pract. 2011;65:397-407.

14. Pratley RE, Nauck MA, Bailey T, et al. Efficacy and safety of switching from the DPP-4 inhibitor sitagliptin to the human GLP-1 analog liraglutide after 52 weeks in metformin-treated patients with type 2 diabetes: a randomized, open-label trial. Diabetes Care. 2012;35:1986-93.

15. Arnolds S, Dellweg S, Clair J, et al. Further improvement in postprandial glucose control when adding exenatide (EXE) or sitagliptin (SITA) to combination therapy with insulin glargine (GLAR) and metformin (MET): a proof-of-concept study. Diabetes Care. 2010;33:1509-15.

16. Violante $\mathrm{R}$, Oliveira $\mathrm{JH}$, Yoon $\mathrm{KH}$, et al. A randomized non-inferiority study comparing the addition of exenatide twice daily to sitagliptin or switching from sitagliptin to exenatide twice daily in patients with Type 2 diabetes experiencing inadequate glycaemic control on metformin and sitagliptin. Diabet Med. 2012;29:e417-24.

17. DeFronzo RA, Okerson T, Viswanathan P, et al. Effects of exenatide versus sitagliptin on postprandial glucose, insulin and glucagon secretion, gastric emptying, and caloric intake: a randomized, crossover study. Curr Med Res Opin. 2008;24:2943-52.

18. Berg JK, Shenouda SK, Heilmann CR, Gray AL, Holcombe JH. Effects of exenatide twice daily versus sitagliptin on 24-hour glucose, glucoregulatory, and hormonal measures: a randomized, double-blind, crossover study. Diabetes Obes Metab. 2011;13: 982-9.

19. Bergenstal RM, Wysham C, Macconell L, et al. Efficacy and safety of exenatide once weekly versus sitagliptin or pioglitazone as an adjunct to metformin for treatment of type 2 diabetes (DURATION-2): a randomised trial. Lancet. 2010;376: 431-9.

20. Wysham C, Bergenstal R, Malloy J, et al. DURATION-2: efficacy and safety of switching from maximum daily sitagliptin or pioglitazone to once-weekly exenatide. Diabet Med. 2011;28: 705-14.

21. Russell-Jones D, Cuddihy RM, Hanefeld M, et al. Efficacy and safety of exenatide once weekly versus metformin, pioglitazone, and sitagliptin used as monotherapy in drug-naive patients with type 2 diabetes (DURATION-4): a 26-week double-blind study. Diabetes Care. 2012;35:252-8.

22. Buse JB, Rosenstock J, Sesti G, et al. Liraglutide once a day versus exenatide twice a day for type 2 diabetes: a 26-week randomised, parallel-group, multinational, open-label trial (LEAD-6). Lancet. 2009;374:39-47.

23. Buse JB, Sesti G, Schmidt WE, et al. Switching to once-daily liraglutide from twice-daily exenatide further improves glycemic control in patients with type 2 diabetes using oral agents. Diabetes Care. 2010;33:1300-3.

24. Buse JB, Nauck M, Forst T, et al. Exenatide once weekly versus liraglutide once daily in patients with type 2 diabetes (DURATION-6): a randomised, open-label study. Lancet. 2013;381:117-24.

25. Drucker DJ, Buse JB, Taylor K, et al. Exenatide once weekly versus twice daily for the treatment of type 2 diabetes: a randomised, open-label, non-inferiority study. Lancet. 2008;372:1240-50.

26. Buse JB, Drucker DJ, Taylor KL, et al. DURATION-1: exenatide once weekly produces sustained glycemic control and weight loss over 52 weeks. Diabetes Care. 2010;33:1255-61.

27. Blevins T, Pullman J, Malloy J, et al. DURATION-5: exenatide once weekly resulted in greater improvements in glycemic control compared with exenatide twice daily in patients with type 2 diabetes. J Clin Endocrinol Metab. 2011;96: 1301-10.

28. DeVries JH, Bain SC, Rodbard HW, et al. Sequential intensification of metformin treatment in type 2 diabetes with liraglutide followed by randomized addition of basal insulin prompted by A1C targets. Diabetes Care. 2012;35:1446-54.

29. Buse JB, Bergenstal RM, Glass LC, et al. Use of twicedaily exenatide in basal insulin-treated patients with type 2 diabetes: a randomized, controlled trial. Ann Intern Med. 2011;154:103-12. 
30. McGill JB, Sloan L, Newman J, et al. Long-term efficacy and safety of linagliptin in patients with type 2 diabetes and severe renal impairment: a 1-year, randomized, double-blind, placebocontrolled study. Diabetes Care. 2013;36:237-44.

31. Hong ES, Khang AR, Yoon JW, et al. Comparison between sitagliptin as add-on therapy to insulin and insulin dose-increase therapy in uncontrolled Korean type 2 diabetes: CSI study. Diabetes Obes Metab. 2012;14:795-802.

32. Vilsboll $\mathrm{T}$, Rosenstock J, Yki-Jarvinen $\mathrm{H}$, et al. Efficacy and safety of sitagliptin when added to insulin therapy in patients with type 2 diabetes. Diabetes Obes Metab. 2010;12:167-77.

33. Barnett AH, Charbonnel B, Donovan M, Fleming D, Chen R. Effect of saxagliptin as add-on therapy in patients with poorly controlled type 2 diabetes on insulin alone or insulin combined with metformin. Curr Med Res Opin. 2012;28:513-23.

34. Drucker DJ, Nauck MA. The incretin system: glucagon-like peptide-1 receptor agonists and dipeptidyl peptidase- 4 inhibitors in type 2 diabetes. Lancet. 2006;368:1696-705.

35. McDougall C, McKay GA, Fisher M. Drugs for diabetes: part 5. DPP-4 inhibitors. Br J Cardiol. 2011;18:130-2.

36. Knudsen LB. Liraglutide: the therapeutic promise from animal models. Int J Clin Pract Suppl. 2010;64:4-11.

37. Deacon CF, Mannucci E, Ahren B. Glycaemic efficacy of glucagon-like peptide-1 receptor agonists and dipeptidyl peptidase- 4 inhibitors as add-on therapy to metformin in subjects with type 2 diabetes-a review and meta analysis. Diabetes Obes Metab. 2012;14:762-7.

38. Lind M, Jendle J, Torffvit O, Lager I. Glucagon-like peptide 1 (GLP-1) analogue combined with insulin reduces HbA1c and weight with low risk of hypoglycemia and high treatment satisfaction. Prim Care Diabetes. 2012;6:41-6.

39. Lane W, Weinrib S, Rappaport J. The effect of liraglutide added to U-500 insulin in patients with type 2 diabetes and high insulin requirements. Diabetes Technol Ther. 2011;13:592-5.

40. Rosenstock J, Shenouda SK, Bergenstal RM, et al. Baseline factors associated with glycemic control and weight loss when exenatide twice daily is added to optimized insulin glargine in patients with type 2 diabetes. Diabetes Care. 2012;35:955-8.

41. Levin PA, Mersey JH, Zhou S, Bromberger LA. Clinical outcomes using long-term combination therapy with insulin glargine and exenatide in patients with type 2 diabetes. Endocr Pract. 2012;18:17-25.

42. Levin $\mathrm{P}$, Wei $\mathrm{W}$, Wang $\mathrm{L}$, et al. Combination therapy with insulin glargine and exenatide: realworld outcomes in patients with type 2 diabetes. Curr Med Res Opin. 2012;28:439-46.

43. Sheffield CA, Kane MP, Busch RS, et al. Safety and efficacy of exenatide in combination with insulin in patients with type 2 diabetes mellitus. Endocr Pract. 2008;14:285-92.

44. Cornell S. Differentiating among incretin therapies: a multiple-target approach to type 2 diabetes. J Clin Pharm Ther. 2012;37:510-24.

45. Amori RE, Lau J, Pittas AG. Efficacy and safety of incretin therapy in type 2 diabetes: systematic review and meta-analysis. JAMA. 2007;298: 194-206.

46. Chia CW, Egan JM. Incretin-based therapies in type 2 diabetes mellitus. J Clin Endocrinol Metab. 2008;93:3703-16.

47. Ross SA, Ekoe JM. Incretin agents in type 2 diabetes. Can Fam Phys. 2010;56:639-48.

48. Duggal R, Menkes DB. Evidence-based medicine in practice. Int J Clin Pract. 2011;65:639-44.

49. Sackett DL, Rosenberg WM, Gray JA, Haynes RB, Richardson WS. Evidence based medicine: what it is and what it isn't. BMJ. 1996;312:71-2.

50. Qaseem A, Humphrey LL, Sweet DE, Starkey M, Shekelle P. Oral pharmacologic treatment of type 2 diabetes mellitus: a clinical practice guideline from the American College of Physicians. Ann Intern Med. 2012;156:218-31.

51. Goldstein BJ, Feinglos MN, Lunceford JK, Johnson J, Williams-Herman DE. Effect of initial combination therapy with sitagliptin, a dipeptidyl peptidase- 4 inhibitor, and metformin on glycemic control in patients with type 2 diabetes. Diabetes Care. 2007;30(8):1979-87.

52. Jadzinsky M, Pfutzner A, Paz-Pacheco E, et al. Saxagliptin given in combination with metformin as initial therapy improves glycaemic control in patients with type 2 diabetes compared with either monotherapy: a randomized controlled trial. Diabetes Obes Metab. 2009;11:611-22.

53. Haak $\mathrm{T}$, Meinicke $\mathrm{T}$, Jones $\mathrm{R}$, et al. Initial combination of linagliptin and metformin improves glycaemic control in type 2 diabetes: a randomised, double-blind, placebo-controlled study. Diabetes Obes Metab. 2012;14:565-74. 
54. DeFronzo RA, Ratner RE, Han J, et al. Effects of exenatide (exendin-4) on glycemic control and weight over 30 weeks in metformin-treated patients with type 2 diabetes. Diabetes Care. 2005;28:1092-100.

55. Nauck M, Frid A, Hermansen K, et al. Efficacy and safety comparison of liraglutide, glimepiride, and placebo, all in combination with metformin, in type 2 diabetes: the LEAD (Liraglutide Effect and Action in Diabetes)-2 study. Diabetes Care. 2009;32:84-90.

56. King AB, Montanya E, Pratley RE, et al. Liraglutide achieves A1C targets more often than sitagliptin or exenatide when added to metformin in patients with type 2 diabetes and a baseline A1C $<8.0 \%$. Endocr Pract. 2013;19:64-72.

57. Davidson JA, Brett J, Falahati A, Scott D. Mild renal impairment and the efficacy and safety of liraglutide. Endocr Pract. 2010;17:345-55.

58. Garber A, Henry RR, Ratner R, et al. Liraglutide, a once-daily human glucagon-like peptide 1 analogue, provides sustained improvements in glycaemic control and weight for 2 years as monotherapy compared with glimepiride in patients with type 2 diabetes. Diabetes Obes Metab. 2011;13:348-56.

59. Garber A, Henry R, Ratner R, et al. Liraglutide versus glimepiride monotherapy for type 2 diabetes (LEAD-3 Mono): a randomised, 52-week, phase III, double-blind, parallel-treatment trial. Lancet. 2009;373:473-81.

60. Scheen AJ. DPP-4 inhibitors in the management of type 2 diabetes: a critical review of head-to-head trials. Diabetes Metab. 2012;38:89-101.

61. Kahn SE, Lachin JM, Zinman B, et al. Effects of rosiglitazone, glyburide, and metformin on $\beta$-cell function and insulin sensitivity in ADOPT. Diabetes. 2011;60:1552-60.

62. Kahn SE, Haffner SM, Heise MA, et al. Glycemic durability of rosiglitazone, metformin, or glyburide monotherapy. N Engl J Med. 2006;355:2427-43.

63. Seino Y, Rasmussen MF, Nishida T, Kaku K. Efficacy and safety of the once-daily human GLP-1 analogue, liraglutide, vs glibenclamide monotherapy in Japanese patients with type 2 diabetes. Curr Med Res Opin. 2010;26:1013-22.

64. Chacra AR, Tan GH, Apanovitch A, et al. Saxagliptin added to a submaximal dose of sulphonylurea improves glycaemic control compared with uptitration of sulphonylurea in patients with type 2 diabetes: a randomised controlled trial. Int J Clin Pract. 2009;63:1395-406.
65. American Diabetes Association. Standards of medical care in diabetes-2013. Diabetes Care. 2013;36(Suppl 1):S11-66.

66. Ishii $H$, Sato $Y$, Takei $M$, Nishio S, Komatsu M. Glucose-incretin interaction revisited. Endocr J. 2011;58:519-25.

67. Marre M, Shaw J, Brandle M, et al. Liraglutide, a once-daily human GLP-1 analogue, added to a sulphonylurea over 26 weeks produces greater improvements in glycaemic and weight control compared with adding rosiglitazone or placebo in subjects with type 2 diabetes (LEAD-1 SU). Diabet Med. 2009;26:268-78.

68. Buse JB, Henry RR, Han J, et al. Effects of exenatide (exendin-4) on glycemic control over 30 weeks in sulfonylurea-treated patients with type 2 diabetes. Diabetes Care. 2004;27:2628-35.

69. Russell-Jones D, Vaag A, Schmitz O, et al. Liraglutide vs insulin glargine and placebo in combination with metformin and sulfonylurea therapy in type 2 diabetes mellitus: a randomised controlled trial (LEAD-5 met $+\mathrm{SU}$ ). Diabetologia. 2009;52:2046-55.

70. Nauck MA, Duran S, Kim D, et al. A comparison of twice-daily exenatide and biphasic insulin aspart in patients with type 2 diabetes who were suboptimally controlled with sulfonylurea and metformin: a non-inferiority study. Diabetologia. 2007;50:259-67.

71. Hermansen K, Kipnes M, Luo E, et al. Efficacy and safety of the dipeptidyl peptidase-4 inhibitor, sitagliptin, in patients with type 2 diabetes mellitus inadequately controlled on glimepiride alone or on glimepiride and metformin. Diabetes Obes Metab. 2007;9:733-45.

72. DeFronzo RA. Banting lecture. From the triumvirate to the ominous octet: a new paradigm for the treatment of type 2 diabetes mellitus. Diabetes. 2009;58:773-95.

73. Zinman B, Gerich J, Buse JB, et al. Efficacy and safety of the human glucagon-like peptide- 1 analog liraglutide in combination with metformin and thiazolidinedione in patients with type 2 diabetes (LEAD-4 Met + TZD). Diabetes Care. 2009;32:1224-30.

74. Elashoff M, Matveyenko AV, Gier B, Elashoff R, Butler PC. Pancreatitis, pancreatic, and thyroid cancer with glucagon-like peptide-1-based therapies. Gastroenterology. 2011;141:150-6.

75. Drucker DJ, Sherman SI, Bergenstal RM, Buse JB. The safety of incretin-based therapies-review of the scientific evidence. J Clin Endocrinol Metab. 2011;96:2027-31. 
76. Nauck MA. A critical analysis of the clinical use of incretin-based therapies: the benefits by far outweigh the potential risks. Diabetes Care. 2013;36:2126-32.

77. Butler PC, Elashoff M, Elashoff R, Gale EA. A critical analysis of the clinical use of incretin-based therapies: are the GLP-1 therapies safe? Diabetes Care. 2013;36:2118-25.

78. Nainggolan L.: Pancreatic cancer and incretins: no signal as yet at NIDDK. Available at: http://www. medscape.com/viewarticle/806287. Accessed July 112013.

79. Davies M, Pratley R, Hammer M, Thomsen AB, Cuddihy R. Liraglutide improves treatment satisfaction in people with type 2 diabetes compared with sitagliptin, each as an add on to metformin. Diabet Med. 2011;28:333-7.

80. Best JH, Boye KS, Rubin RR, et al. Improved treatment satisfaction and weight-related quality of life with exenatide once weekly or twice daily. Diabet Med. 2009;26:722-8.

81. Best JH, Rubin RR, Peyrot M, et al. Weight-related quality of life, health utility, psychological wellbeing, and satisfaction with exenatide once weekly compared with sitagliptin or pioglitazone after 26 weeks of treatment. Diabetes Care. 2011;34:314-9. 